\title{
Code and the Transduction of Space
}

\author{
Martin Dodge* and Rob Kitchin** \\ *Centre for Advanced Spatial Analysis, University College London \\ **Department of Geography and NIRSA, National University of Ireland, Maynooth
}

\begin{abstract}
The effects of software (code) on the spatial formation of everyday life are best understood through a theoretical framework that utilizes the concepts of technicity (the productive power of technology to make things happen) and transduction (the constant making anew of a domain in reiterative and transformative practices). Examples from the lives of three Londoners illustrate that code makes a difference to everyday life because its technicity alternatively modulates space through processes of transduction. Space needs to be theorized as ontogenetic, that is, understood as continually being brought into existence through transductive practices (practices that change the conditions under which space is (re)made). The nature of space transduced by code is detailed and illustrated with respect to domestic living, work, communication, transport, and consumption. Key Words: everyday life, code, ontogenesis, transduction, technicity, space.
\end{abstract}

[S]pace is neither absolute, relative or relational in itself, but it can become one or all simultaneously depending on the circumstances. The problem of the proper conceptualization of space is resolved through human practice with respect to it.

-(Harvey 1973, 13, italics original, our underline).

S oftware, commonly referred to as code, is increasingly central to the spatial formation of collective life. Code produces, monitors, surveys, augments, and controls many aspects of daily living, including the infrastructures of communication, transport, finance, and utilities such as water and electricity. Indeed, such is the importance of code that everyday tasks associated with work, travel, communication, consumption, health, and domestic living are ever more dependent on code for their functioning. In some cases, this dependence is so great that if the code "crashes,"1 then the task cannot be completed because manual alternatives have been discontinued or are inadequate to cope with demand. For example, the "crash" of the air traffic control system at Tokyo Air Traffic Control Center, 1-2 March 2003, meant the cancellation of over 203 flights, with flights resuming only after the system was reestablished (Risks List 2003). Seemingly minor failures in relatively insignificant software systems for routine monitoring can have very serious consequences, as demonstrated by the large-scale power outage affecting millions of people in Northeast United States and Canada in August 2003. Official reports conclude that a software failure in the alarm system in the control center of FirstEnergy in Akron, Ohio was a significant contributing factor (U.S.-Canada Power System Outage Task Force 2004). Perhaps the best illustration of the contemporary social and economic importance of code was the global panic associated with the Y2K "millennium bug," which triggered a worldwide overhaul of operating systems. The cost to the U.S. federal government alone was estimated at $\$ 8.34$ billion, while governments and businesses across the world spent an estimated \$200-600 billion to address the problem (Bennett and Dodd 2000). And yet, despite the growing use and pervasiveness of code in contemporary society, code and its effects on the production of space have largely been ignored by geographers in favor of studying the technologies and infrastructures that code facilitates (although see Thrift and French 2002). Accordingly, this article provides an analysis of the effects of code on daily life and the production of space and explains the difference code makes through an interrogation of the relationship between technology, society, and space.

To structure the discussion, the article is divided into six sections. The first section details the form and nature of code and provides a typology of the various ways it is embedded in everyday objects, infrastructures, and processes. The extent and effects of code on everyday life are then illustrated through three vignettes, each of which details a day in the life of an individual living in London. In the third section, a theoretical framework for understanding the effects of code and making sense of the vignettes is developed. This framework draws on the ideas of Bruno Latour, Guy Simondon, and Adrian Mackenzie and utilizes the concepts of technicity (the productive power of technology to make things happen) and transduction (the constant making anew of a domain in reiterative and transformative practices) to explain the difference code makes to everyday life. In the following section, these theoretical ideas are extended to 
argue that one of the prime reasons why code makes a difference to everyday life is because its technicity alternatively modulates space through the process of transduction. Here, an ontogenetic ${ }^{2}$ understanding of space is developed in which space is understood as continually being brought into existence through everyday transductive practices. In the fifth section, the nature of transduced space is elaborated, and in the final section, the vignettes are used to illustrate various code-induced spatial transductions with respect to domestic living, work, communication, transport, and consumption.

\section{The Nature of Code}

For the purposes of this article, code consists of instructions and rules that, when combined, produce programs capable of complex digital functions that operate on computer hardware. We therefore use the term code in a restricted sense to refer to the rules and instructions of software rather than broader notions of codes as sociocultural structures and technical/legalistic protocols of ordering and control, such as national laws, international treaties, etiquette, standards, systems of measurement, institutional customs, and professional codes of conduct. Code, as software, takes multiple forms, including hard-coded applications with no or limited programmability (e.g., embedded on chips in alarm clocks, GPS receivers), specialized applications (e.g., banking software, traffic management systems), generic applications (e.g., word processing, spreadsheets, web browsers) and operating systems (e.g., Windows, MacOS, Unix, Linux) that run on a variety of hardware (e.g., embedded chips, dedicated units, PCs, workstations) and can distribute, generate, monitor, control data exchange and flow across a range of infrastructures (e.g., printed circuit boards, coaxial and fiberoptic cables, wireless, satellites) using a variety of forms (e.g., electrical, light, microwave, radio). The coding within these programs varies from abstract machine code and assembly language to more formal programming languages, applications, user created macros, and scripts. These forms of code are embedded in everyday life in at least four main ways, producing what we term coded objects, coded infrastructures, coded processes, and coded assemblages.

Coded objects refer to non-networked objects that use code to function or permanently store digital data that cannot be accessed without software. The former range from simple household items such as alarm clocks, "smart" irons or kettles, televisions, washing machines that use basic code to augment their use, through to complex, but isolated machines, such as DVD players and PCs. The latter include credit and cash cards, floppy disks, and CD-ROMs. Though these coded objects vary in their scope, sophistication, and programmability, the importance of code to their function is such that if the code (or hardware that supports it use) fails or miscomputes, the object ceases to function as intended (e.g., a cash card fails to work as a cash card). In all cases, unless networked, the remit of the code is limited purely to that object.

Coded infrastructures refer both to networks that link coded objects and infrastructure that is monitored and regulated, either fully or in part, by code. Such coded infrastructure (or ensembles) include distributed infrastructures such as computing networks (e.g., Internet, intranets), communication and broadcast entertainment networks (e.g., mail, telephone, mobile phones, television, radio, satellite), utility networks (e.g., water, electricity, gas, sewerage), transport and logistics networks (e.g., air, train, road, shipping), financial networks (e.g., bank intranets, electronic fund transfer systems, stock markets), security and policing networks (e.g., criminal identification databases, surveillance cameras), and relatively small-scale and closed systems such as localized surveillance (say, within one building complex), and small but complex systems such as a individual car. The geographical coverage of distributed infrastructures thus varies from global coverage, as with GPSs (which, literally, can be accessed from any point on the Earth) to more localized coverage.

In all these infrastructures, code is now an integral component in complex systems that consist of electronic, electrical, mechanical, and physical components. Within an infrastructure, these components are organized hierarchically, with components becoming more complex and more significant toward the top of the hierarchy and, at the same time, tending to become less numerous and less visible. If we take the example of the car as a relatively closed coded infrastructure, the physical components would be the body shell, the wheels, the seats, and so on, as well as the fuel; the mechanical would be the pistons, the gears, the brakes; the electrical would be the ignition system, the battery, the lights, the radio; the electronic would be the fuel gauge, the engine temperature sensor, the alarm and immobilizer, and so on; the code would be the various "black boxes" such as the engine management system that monitors the car, continuously adjusting for performance, road conditions, and driver demands. The result of these black boxes is that for most modern-day cars, there is no longer a direct electromechanical connection between the key in the ignition and the start of the engine. Code mediates and 
dominates this transaction. In the case of a distributed network such as a water utility system, ${ }^{3}$ while the vast bulk of the infrastructure is still "dumb," consisting of pipes, valves, pumps, taps, and so on that are not coded objects, the network is now likely to be operated and regulated by code (programs for monitoring water quality, reservoir levels, and channeling water supplies through network of pipes; measurement and billing software for charging customers). Water is still water, and the network still "dumb" pipes, but the flow of water is now dependent on code.

Coded processes refer to the transaction and flow of digital data across coded infrastructure. Here, the flow of data consists of more than simple instructions to regulate coded objects within an infrastructure. Rather, the flow consists of the transfer of information. Flows become particularly important when they involve the accessing, updating, and monitoring of relational databases that hold individual and institutional data. Such databases can be accessed at a distance and used to verify, monitor (say for billing purposes), and regulate user access to a network, update personal files, and so on. An example of a coded process is the use of an ATM. Here, data and transaction flow are transferred across the coded infrastructure of the bank's secure intranet based on access via a coded object (the customer's bank card), verifying the customer based on a personal identification number (PIN), determining whether a transaction will take place, instructing the ATM to complete an action, and updating the user's bank account. Part of the power of relational databases is that they hold common fields that allow several databases to be cross-referenced and compared. Other coded processes center on databases relating to mortgages, shares, taxation, insurance, health, crime, utility usage, service usage, and so on, all of which can be accessed across open or, more commonly, closed networks. While coded processes are largely invisible and distant, they are revealed to individuals through letters, statements, bills, receipts, print-outs, licenses, and so on, and through unique personal identification numbers on the coded objects used to access them (e.g., bank and credit cards, library cards, transport season tickets, store loyalty cards) (Dodge and Kitchin forthcoming).

Coded assemblages occur where several different coded infrastructures converge, working together-either in nested systems or in parallel, some using coded processes, others not-and, over time, become integral to one another in producing particular environments, such as office complexes, transport systems, and shopping centers. For example, the combined coded infrastructures and coded processes of billing, ticketing, check-in, baggage routing, security, safety, customs, immigration, air traffic control, airplane instruments, work together to create a coded assemblage that defines and produces airports and passenger air travel (see Dodge and Kitchin 2004). Similarly, the coded infrastructures of water, electricity, gas, banks and mortgage lenders, commodities, Internet, telephone, mail, television, government database systems, and so on, work together to create an assemblage that produces individual households. The power of these assemblages is their interconnection and interdependence, creating systems whose complexity and power are much greater than the sum of their parts.

These elements, taken together, make it clear that code is something very difficult to avoid; code makes a difference to the constitution and material and discursive practices of everyday life. It is now almost impossible not to live within the orbit of code, anywhere on the planet. To do so would mean being born outside of collective life so that one does not appear in government databases, does not use any utilities (e.g., water, electricity), does not use modern convenience items (e.g., kettle, washing machine), does not watch or take part in entertainment or recreational activity (e.g., television, cinema), and avoids consumptive and societal activities such as shopping (thereby avoiding barcodes, credit cards, surveillance cameras, and the like). In short, code, to varying degrees, conditions existence.

\section{Three Vignettes}

$[\mathrm{M}]$ ore and more ... the spaces of everyday life come loaded up with software (Thrift and French 2002, 309).

The extent and effects of code on everyday life can be illustrated by considering the daily lives of people and the extent to which code mediates, augments, regulates, and facilitates their activities. The three vignettes presented in this section each depict a day in the life of an individual living in London. Each individual lives in a different part of the city (reflective of income and class) and works in a different occupational sector. (Table 1 provides part of the ACORN geodemographic profiles of the residential locations.) While the individuals themselves are fictions, the coded assemblages of homes, work places, recreational sites, and the routes between them, along with coded objects, infrastructures, and processes encountered in those assemblages, are real (and were observed in situ through fieldwork on 25 and 26 June $2003^{4}$ ). We believe that the vignettes are not extreme or exceptional cases and are representative of how code is embedded in the daily lives of individuals living in the city. While the vignettes concentrate on individual narratives, it should be clear that the effects that occur 
Table 1. Geodemographic Details of the Three Vignettes Based on Their Residential Postcode Location (Source: ACORN geodemographic produced by CACI. Obtained from http://www.upmystreet.com.)

\begin{tabular}{lccc}
\hline Vignette & Naomi (postcode - SE1 6SX) & Elizabeth (postcode - N22 5DT) & John (postcode - BR7 5QE) \\
\hline & Type 47: Estates with & Type 38: Multiethnic areas, & Type 1: Wealthy suburbs, \\
ACORN type & high unemployment & white collar workers & large detached houses
\end{tabular}

Socioeconomic The unemployment rate is nearly profile

Durables

Financials

Media double the national average. The proportion of people working in the service sector is 14 percent above average, and there is a correspondingly lower than average proportion of manufacturing workers. The level of secretarial and clerical workers is 28 percent higher than average. There are also 61 percent more unskilled workers than average. The proportion of people travelling to work by public transport is 2.7 times higher than average; in particular, 3.6 times more people than nationally travel to work by train.

Car ownership levels are very low-64 percent of households have no car. The proportions of new and expensive cars and company cars are very low. A number of durable products are purchased at above average rates by people in these areas: computer games, microwaves, washing machines, washer/ dryers, tumble dryers, and fridge freezers. Other products are purchased at well below average rates. Home improvement activity is practically nonexistent.

Although there are 37 percent more people than average with incomes under $£ 5,000$ per annum, over a quarter earn more than $£ 25,000$ per annum. Ownership of financial products is very low, and there are scarcely any new, current, or savings accounts being opened.

The proportion of homes with cable television is over double the average, but satellite television ownership is 5
The unemployment rate is 56 percent higher than average. The proportion of people working in the service sector is slightly above average, but there are 30 percent fewer than average manufacturing workers. There is a broad mix of occupations across the socioeconomic scale, but the largest concentration is in the skilled, nonmanual category. There are also above average numbers of students in these areas. Public transport is the dominant mode of travel to work; in particular, the proportion of people using rail is 4.7 times higher than average.

Thirty-four percent fewer households than average have a car. Company car ownership is 29 percent higher than average. Typically, cars are small, 2-4 years old, and costing under $£ 10,000$. People in this ACORN Type are more likely than average to purchase the following durables: hardback books, computer games systems and games, video cameras, and ski clothing. Purchase rates for most household durables are very low, with the exception of fridge freezers. The proportion of homes having secondary glazing fitted is 50 percent above average.

The income profile of these areas peaks in two places. The proportion of people earning $£ 10-15,000$ per annum is slightly above average, and there are 47 percent more people than average earning £30-40,000 per annum. Ownership of financial products is generally lower than average-much lower than might be expected, given the income profile. The rate of new savings account opening is 32 percent above average, while people are 15 percent more likely than average to have a mortgage from a lender other than a building society.

The number of homes with cable television is almost three times higher than average, while satellite television
ACORN Type 1 comprises a highly educated population: almost three times the national level of residents have degrees. In terms of employment, these are largely professional and managerial people. Unemployment is around a third of the national level.

Levels of car ownership are very high: 3.5 times the national level of households have three or more cars. Cars are likely to be new, large, and very expensive. The proportion of cars costing over $£ 20,000$ is nearly ten times higher than average, and the proportion of $2500 \mathrm{cc}+$ cars is nearly four times higher than average. The incidence of company cars is also above average-at 13 percent, this is three times higher than the national rate. There is not a great deal of home improvement activity in these areas. Purchase rates of white and brown goods are average. Installation rates for new central heating and double glazing are well below average.

These are extremely high income areas - the proportion of households earning more than $£ 40,000$ per annum is 5.4 times higher than average. Ownership of National Savings Certificates is 2.8 times higher than average, and there are also well above average holdings of stocks and shares, all plastic cards, and personal pensions.

By far the most popular daily newspaper is The Telegraph, which has a readership level 3.5 times higher than average. The 
Table 1. (Contd.)

\begin{tabular}{|c|c|}
\hline Vignette & Naomi (postcode - SE1 6SX) \\
\hline ACORN type & $\begin{array}{l}\text { Type 47: Estates with } \\
\text { high unemployment }\end{array}$ \\
\hline & $\begin{array}{l}\text { percent below average. Readership of } \\
\text { daily newspapers is concentrated } \\
\text { basically on two titles: The Mirror and } \\
\text { The Sun. The Sunday papers with the } \\
\text { largest readerships are The News of the } \\
\text { World, The Sunday Mirror, and The } \\
\text { Sunday People but The Observer is read } \\
\text { by twice as many people here as } \\
\text { average. Both ITV viewing and } \\
\text { commercial radio listening are heavy. }\end{array}$ \\
\hline
\end{tabular}

Elizabeth (postcode - N22 5DT) John (postcode - BR7 5QE)

Type 38: Multiethnic areas, white collar workers
Type 1: Wealthy suburbs, large detached houses penetration is 10 percent up on the average. A wide range of newspapers are popular in these areas. Readership of The Independent is 2.3 times higher than average, while that of The Guardian, The Mirror, and The Sun are all around 60 percent above average. All the national Sunday titles except The Sunday Express, and The Mail on Sunday have higher than average readerships. ITV viewing is light, but commercial radio listening is heavy.
Leisure

\begin{abstract}
Fifty percent of people do not take
\end{abstract} holidays at all. Those who do are 31 percent more likely to go to a far-flung destination. Their propensity to visit pubs, clubs, and wine bars regularly is roughly average, but they are much less likely to eat out. Participation rates for most sports are very low, but football, cricket, fishing, and table tennis are more popular than average. Extremely popular activities are betting, bingo, darts, and snooker.
The proportion of people taking holidays is about 13 percent less than average. People who do go on holiday, however, are much more likely than average to go away in the winter, to take a long holiday and to go to far-flung destinations. People are less likely than average to go to pubs, clubs, and wine bars and to eat out during the day. Their propensity to eat out in the evenings is average, and a wide range of restaurant types are popular. Italian and British cuisine is less popular than average in these areas though. These are very active, busy people. Sporting and other activities which are particularly popular with people in ACORN Type 38 are: running, cricket, athletics, squash, skating, skiing, climbing, and going to the cinema and art galleries.
Times is read by almost five times more people in these neighbourhoods than nationally, and readership of The Financial Times is also over three times higher than average. The most widely read Sunday newspaper is The Sunday Times, which is read by 3.3 times more people in this ACORN Type than nationally. The readership of The Sunday Telegraph is 4.2 times higher than average, and both The Observer and The Independent on Sunday are more than twice as popular as nationally. ITV viewing levels are very low, with 57 percent of people classified as light viewers. Commercial radio listening levels, however, are average.

Winter holidays and long holidays are very popular, and the proportion of people holidaying in their own holiday home or timeshare is over three times higher than average. Gardening is a popular activity. People are less likely than average to go to pubs, clubs, and wine bars, but much more likely than average to eat out, with French, Italian, and Greek cuisines all being highly favored. People in these neighbourhoods are very active, with above average participation rates in many sports. Tennis, skiing, sailing, windsurfing, and ten-pin bowling are particularly popular. Theater attendance is over twice the national rate, and people are much more likely than average to visit stately homes. are not simply of individual and code, but are largely manufactured collectively, mediated by the presence of others (indeed, they are part of complex sociotechnological relations). Here, for purposes of illustration, we want to concentrate on individual rather than collective production.

\section{Naomi}

Naomi is in her early thirties. She is married with three children and lives in Draper House, a tower block close to the Elephant and Castle (site of a large shopping mall and major road intersection in the borough of
Southwark in inner south London) (Table 1). Her day starts at 6:30 a.m. when her youngest child wakes her. For the next two hours she prepares breakfast and gets the children ready for school. The two youngest children watch satellite television while the eldest stays in his bedroom playing on his Xbox. Her husband returns home from working a nightshift at 8:10 a.m. She checks the electricity meter to see if the payment card needs topping up, and at 8:25 she and the children leave the flat and take the lift to the ground floor foyer of the block, where they are filmed by the council housing security camera network, installed to deter strangers and vandalism. They leave through a security door and head 
toward the Elephant and Castle Day Nursery on Hampton Street. She drops off the youngest child and is filmed at the door by a single, miniature security camera. She then walks down Canterbury Place, onto Peacock Street, leaving her other two children at Crampton Primary School.

At 8:45 Naomi largely retraces her steps, passing Draper House, and heading toward the Elephant and Castle Shopping Centre. She negotiates the busy road via a pedestrian underpass, which is equipped with Closed Circuit Television (CCTV) cameras at entrances and exits. At street level, she passes workmen excavating the pavement to repair cables. At the entrance to the shopping center, she is filmed by the private security system for the center, and three more large dome cameras cover her passage through the center. She enters the Tesco Metro supermarket where she works and is assigned a checkout station by the store manager. Logging onto the checkout, she is recognized by the store's computer system, which begins to log her performance. The store itself is covered by a number of dome surveillance cameras monitoring the customers and also the staff. She spends the day seated at the checkout, serving customers, scanning products, processing payments, and logging customer loyalty cards. Her checkout screen informs her of required actions.

At lunchtime, she eats a sandwich in the canteen while speaking to her sister on a prepaid mobile telephone, arranging a weekend family get together. She also pops into the KNS News and Food Store on Newington Butts, the nearest PayPoint facility to her place of work, to top up her electricity payment card and to buy a lottery ticket. She is filmed by the store's interior CCTV. She returns to work in the afternoon for a short period before leaving at 3:20 to collect the children from nursery and school. Arriving back at Draper House at 4:00, she accesses the tower with an electronic key fob. She charges up the electricity meter and then prepares dinner, while the children watch satellite television. At 6:30 she takes the kids to the playground next to tower block, where she chats with neighbors for an hour. At 8:30 she puts the children to bed, and at 9.30 her husband leaves for work. She watches television for an hour and then goes to bed herself.

\section{Elizabeth}

Elizabeth is in her late twenties and lives on her own in a one-bedroom flat on lower Eldon Road, in Noel Park, near Wood Green in the inner suburbs of north London (Table 1). She works as an anesthetist in St Bart's Hospital, near to St Paul's in central London.
Elizabeth's day starts at 7:00 a.m. After an hour of getting ready, she heads out of the house, turning her iPod on, and walks down Eldon Road, crosses Lordship Lane, and walks along Moselle Street. At the end of the street, she turns right onto The Broadway under the gaze of two private security cameras stationed above an estate agent's. She waits at the curb of Bull Road as three double-decker buses pass. The buses, unbeknown to her, transmit their locations to a small transponder box mounted on a lamppost that updates the estimated arrival time on the "countdown" digital displays along the buses' routes. She crosses the road and walks past one such bus stop, another transponder, under the gaze of a cluster of six security cameras that provide full coverage of the front of a cinema and entertainment complex. She skirts a council information kiosk that gives details on local services, ignoring the electronic screen, and waits at the crossing of Lordship Lane for the traffic lights to change. On the other side of the road, she waits at a short queue at Barclays Bank ATM and withdraws fifty pounds, her account automatically being updated with the time, place, and amount withdrawn. She receives a printed receipt.

Just after 8:10, she heads into the Tube station. She waves her "smart" card ticket over a transponder, and the ticket barrier opens, a debit is taken against her card, and she is logged into the Underground monitoring system. Around her, a cluster of five security cameras, part of the Underground's integrated passenger management and security system that covers the entire network, tracks her and the other customers' movements as she descends to the platform where four more cameras are located. After a couple of minutes wait, glancing up at an arrivals information display, she boards a southbound train, and standing, reads her book. For twenty minutes, she travels on the Northern Line to Holborn, where she changes to the Central Line, passing eight cameras as she wanders through the connecting tunnels between platforms, listening to her music and blocking out the background noise of an automated security message not to leave baggage unattended. As she walks onto the platform, an eastbound train arrives, and she travels the short distance to St Paul's station, where she again passes under the gaze of several cameras, and exits, swiping her smart-card ticket again to open the barrier. She reaches ground level at 8:40, and her mobile telephone bleeps to let her know a text message is waiting. As she waits in the throng of commuters for the lights to cross Martin's Le Grand, she uses her mobile phone to text her friend Sally about meeting up that evening. She crosses the road and heads up Newgate Street, turning into King Edward Street. Again, she 
passes several security cameras before turning into the entrance of St Bart's.

She enters the hospital at 8:55 and turns off her iPod. After checking her internal mail, she gossips with colleagues, checks her schedule, makes sure her pager is activated, and then starts her rounds with patients, first looking up their records on a computer database. She passes through the hospital under the gaze of a plethora of surveillance cameras and uses a swipe card to pass through doors that have restricted access. She leaves the hospital at 12:30 with a colleague and has lunch at Caffe Nero on Newgate Street, paying with cash. She makes two mobile phone calls to friends and rings up her insurance company to make a query about her home insurance bill. The insurance agent explains that the rate has been set using a computer package that uses demographic and crime data. She returns to the hospital at $1: 20$. In the afternoon, she is on duty in the operating theater, administering the anaesthetic to patients she consulted earlier. The effects of the anaesthetic and the progress of the operations are monitored by sophisticated healthcare equipment.

After responding to a last-minute pager call, she leaves the hospital at 5:12 and retraces her Tube route to Wood Green station. On exiting the station, she crosses the road beneath a traffic camera and enters a Safeway supermarket, passing through the magnetic gates, which scan for antitheft tags. She buys some groceries for her evening meal, paying with a credit card, which logs her transaction and its location, and heads home. On opening the door, she finds two letters and a small parcel on the doormat. One letter is an itemized mobile telephone bill (which has been paid automatically by direct debit), the other a piece of targeted junk mail inviting her to open another credit card account. The small parcel contains two compact discs from Amazon.co.uk, plus a discount coupon as an incentive to buy other CDs selected by their customer profile system based on previous purchases. She cooks dinner, using a microwave, and watches some television before going on-line, using a dial-up connection, to check her e-mail. After typing some responses and deleting some spam (e-junk mail), she looks up responses to her advertisement on an Internet dating service and the web pages for the local cinema to see what films are playing and then browses the British Broadcasting Corporation (BBC) news site. At 8:15, after a call from Sally on her mobile, she heads out to The Goose pub near Wood Green station to meet Sally and some other friends. She is filmed by the cameras on The Broadway and when entering the pub. She receives several text messages while with her friends. She returns home at $11: 30$.

\section{John}

John is forty-eight years old, married with two teenaged children. He lives in a large detached house in Chislehurst in the outer suburbs of southeast London (Table 1). His day starts at 6:45 a.m. when the digital radio alarm clock sounds. After a shower, he dresses, has breakfast, and checks the mail. He has an electricity bill that has already been paid by direct debit. He then collects his laptop, PDA, and $3 \mathrm{G}$ picture phone from his study and heads to the garage, passing under the discrete CCTV camera mounted on the side of the garage to monitor the driveway. As he approaches the car, he uses a remote control to open the garage door, and unlocks his BMW with a remote radio fob. On starting the car, the vehicle's management system undertakes a series of system checks.

He turns onto Manor Park and switches on the digital radio, automatically picking up real-time traffic reports. He has his in-car navigation system turned off. He drives into the city center along the A20, A2, and through the Blackwall Tunnel, passing through a series of traffic cameras, red light cameras, and speed cameras, responding appropriately. He receives a call on his mobile phone, which he answers with a "hands free" unit, from the office in Singapore, giving him a progress report on a merger negotiation. As he approaches Aldgate East, a congestion charge camera recognizes his license plate and automatically checks that he has prepaid the fee. At Bishopsgate, he passes into the "ring of steel," a concentrated set of high-security cameras that surround the City; again, his license plate is logged. At his work place, a large office complex on Finsbury Square, he turns into a small side street, and a barrier rises in response to a transponder in the car. He drives into the subterranean car park, parking in a designated slot. He stands under a security camera, calls the lift using a swipe card, and ascends to his office floor. He gains access to his corridor again using a swipe card. Once in his office, he checks the fax machine, logs onto his computer to check e-mail, and docks his PDA to update his shared diary. At 9:00 he confers with his secretary to confirm his schedule and liase about work.

From 9:00 until 10:10, he answers e-mail and takes a couple of telephone calls. At 10:15, he moves to a small boardroom for a meeting. On the table is a speakerphone that connects the room to colleagues in Singapore. From 10:50 until lunchtime, he works on compiling a report and producing tables and charts. For lunch, he joins a client at a small bistro, where he pays for the meal with his credit card. In the afternoon, he catches up with his e-mail, monitors financial transaction data, takes calls 
from colleagues and clients, and continues to write his report. At 4:30 he receives a text message from his wife to say that she and the children are going to the cinema. At 5:35, he uploads his updated diary to his PDA, shuts down his computer, and heads up to a private gymnasium on the top floor, where he works out on machines equipped with fitness and health monitors. After showering, he descends to the car park and heads out of the city to his home, retracing his earlier route. On arrival, he enters the house and turns off the motion-sensor alarm system, using a keypad. He connects his laptop computer to the broadband Internet connection and checks e-mail from the New York office, replying where necessary. He then checks his share prices on a financial website. At 8:00 his wife and children return. At 10:00 he watches a satellite-delivered news channel for twenty minutes to catch up on world events. $\mathrm{He}$ and his wife retire to bed at 11:10.

\section{The Power of Code}

The three vignettes highlight the effect of code on everyday life in relation to home, work, transport, communication, and consumption and show how code mediates, supplements, augments, monitors, regulates, facilitates, and produces collective life. While these vignettes can be read uncritically in an empiricist or deterministic manner, making sense of the difference code makes to everyday life requires a nuanced analysis. Code does not simply exist, created and working in easily defined and examined ways. Code, and the hardware and infrastructures it operates and communicates across, following Latour (1993), need to be recognized and theorized as the outcomes of "complex interactions involving the commodity production, organizational life, technoscientific knowledges and enterprises, the organization of work, manifold identities and geo-politicaltechnological zones of contact" (Mackenzie 2003a, 3). Code is bound up in, and contributes to, complex discursive and material practices, relating both to living and nonliving humans and technology, which work across scales and time. In this view, society consists of collectives that are hybrid assemblages of humans and nonhumans (Latour 1993), wherein the relationship between human and technology is complex, contingent, relational, and productive.

The indeterminacy and contingency that technology induces "neither belongs solely to human life nor belongs to some intrinsic dynamism of technology" (Mackenzie $2002,10)$ but, rather, human life and technology are produced through, or folded into, each other in complex ways. Technologies thus need to be understood "proc- essually ... as events rather than objects, as contingent the whole way down"; "as networks of social-material interactions rather than simply reflections of human capacities or innately alien objects" (Mackenzie 2003b, $4,8)$. In other words, it makes little sense to conceive of either humans or technology without reference to the other. As such, the distinction between living and nonliving (technological), wherein humans shape or are shaped by technology, is rendered problematic (Mackenzie 2002). Instead of there being an interface between humans and technology, they become entwined as hybrids. To understand technology, then, means to comprehend the ways in which technology is plotted, designed, made; to understand humans means to comprehend their relationship with the nonliving (e.g., coded objects) and nonhumans (e.g., landscapes, animals) (Whatmore 2002). This understanding necessitates a nuanced reading of the work that code, in conjunction with people, does and how this work unfolds in practice. A profitable way to achieve such an understanding is to employ the concepts of technicity and transduction.

\section{Technicity}

[T]echnicity and transduction account for how things become what they are rather than what they are (Mackenzie 2002, 16, our emphasis).

The extent to which code is embedded in everyday society (as objects, infrastructure, processes, and assemblages) is not the same thing as the extent to which it makes a difference to everyday life. The power of code to transform everyday life is not simply a function of extent or pervasiveness or visibility, but primarily of effect. Technicity refers to the extent to which technologies mediate, supplement, and augment collective life; the extent to which technologies are fundamental to the constitution and grounding of human endeavor; and the unfolding or evolutive power of technologies to make things happen in conjunction with people (Mackenzie 2002). For an individual technical element such as a saw, its technicity might be its hardness and flexibility (a product of human knowledge and production skills) that enables it, in conjunction with human mediation, to cut well (note that the constitution and use of the saw is dependent on both human and technology; they are inseparable). As Star and Ruhleder (1996, 112; our emphasis) note, "[A] tool is not just a thing with pregiven attributes frozen in time - but a thing becomes a tool in practice, for someone, when connected to some particular activity ... The tool emerges in situ." "In large-scale ensembles, such as an automobile engine 
consisting of many components, technicity is complex and cannot be isolated from the sum of individual components (and their design, manufacture, and assembly), its "associated milieu" (e.g., flow of air, lubricants, fuel), and its human operator(s), that "conditions and is conditioned by the working of the engine" (Mackenzie 2002, 12).

As the vignettes demonstrated, code is productive; it possesses high technicity. Code enables everyday acts to occur, such as watching television, using the Internet, traveling across a city, buying goods, making transnational phone calls, operating healthcare equipment, and withdrawing money from an ATM. While some of these practices were possible before the invention of code, code is now vital to their operation, and in some cases possible only through the work of code. The technicity of code is not, however, deterministic (i.e., code determines, in absolute, nonnegotiable means, everyday practices) or universal (i.e., such determinations occur in all places and at all times in a simple cause-and-effect manner). Rather, as noted, technicity is contingent, negotiated, and nuanced; it is realized through its practice by people in relation to historical and geographical context. As such, there is no neat marriage between coded objects, infrastructures, processes and assemblages, and particular effects of code. Instead, technicity varies as a function of the nature of code, people, and context.

The technicity of code varies, depending on the autonomy and consequences of code. Autonomy relates to the extent to which code can do its "work" without direct human oversight or authorization. The degree of autonomy is a function of the amount of input (the system's knowledge of its environment and memory of past events), sophistication of processing, and the range of outputs code can produce. If code "crashes" then the consequences of its failure can range from mild inconvenience (e.g., travel delays) to serious economic and political impacts (e.g., failure of the power grid) to lifethreatening situations (e.g., vital medical equipment unable to function or air traffic control unable to direct planes). All types of code do not, therefore, have similar qualities or impacts. For example, the technicity of code employed in the London Underground is radically different from that employed in a hospital intensive care unit.

Further, the technicity of code varies as a function of the nature of individuals. Not all individuals experience or interact with the same code in the same way, depending on their personality, characteristics (e.g., gender, class, race), status, individual reflexivity, their personal histories and experiences, whether they are working or passing through a place, their intentions, their technical competencies, whether they are on their own or in groups, and so on. As the definition of technicity denotes, code and its effects are peopled. For example, somebody familiar with a computer system may experience that system in a more banal and ambivalent way than somebody using it for the first time.

The relationship between code and people also varies as a function of wider context. Mobilities, transactions, and interactions that involve code are historically, geographically, and institutionally embedded and do not arise "from nowhere." Rather, the code works within conventions, standards, representations, habits, routines, practices, economic climates, discursive formations, and so on, that position how code engages and is engaged with. The use of code is then always prefaced by, and contingent upon, this wider context.

\section{Transduction}

A "happening in the world" is what needs to be understood. From time to time, and always in time, new forms emerge that catalyse previously existing actors, things, temporalities, or spatialities into new modes of existence, a new assemblage, one that makes things work in a different manner and produces and instantiates new capacities. A form/event makes many other things more or less suddenly conceivable (Rabinow 1999, 180; cited in Mackenzie 2003b, 3).

Technicity is realized through the process of transduction (a concept developed by Adrian Mackenzie (2002, 2003b) from Gilbert Simondon's (1989a, b, 1992, 1995) work). For Mackenzie, "transduction is a kind of operation, in which a particular domain undergoes a certain kind of ontogenetic modulation. Through this modulation, in-formation or individuation occurs. That is, transduction involves a domain taking-on-form, sometimes repeatedly" (2003b, 10, his emphasis). Transduction, then, is a process of ontogenesis, the making anew of a domain in reiterative and transformative individuations. According to Simondon (1992, 313), "[t]he simplest image of the transductive process is furnished if one thinks of a crystal, beginning as a tiny seed, which grows and extends itself in all directions in its mother-water. Each layer of molecules that has already been constituted serves as the structuring basis for the layer that is being formed next, and the result is amplifying reticular structure."

Individuation can consist of speech acts, physical actions, occurrences, memories, perceptions, and so on. The process of individuation results in a modulation in conditions of the person and his or her milieu. Most individuations are ordinary, reiterating previous 
individuations (e.g., placing one foot in front of the other); others are singular and result in radical transformation (e.g., starting, stopping, changing direction). Ordinary individuations are routine and banal. Individuations are citational in that they imperfectly cite previous individuations, as in Butler's (1990, 1993) theory of performativity. The process of individuation in domains of living things is ongoing; an individuation may provisionally solve a problem within a domain, but these are replaced by new problems. For example, as the vignettes illustrated, a person traveling through a city constantly changes his or her relation to their milieu, thus posing a continuous supply of new problems such as maintaining a bearing, avoiding obstacles and traffic, and reacting to surrounding situations such as traffic lights, speed cameras, requests for tickets, and so on. As such, "[t]hrough transduction, a domain structures itself as a partial, always incomplete solution to a relational problem" (Mackenzie 2003b,10).

Code solves relational problems by acting as a catalyst for transductions to occur and sustaining individuations within a modulation. Code changes the conditions through which everyday life occurs because it modulates how other technologies function. Code enhances the technicity of coded objects and infrastructures, enabling them to perform as intended; using a computer to access an online shop transduces, that is, alternatively modulates, how a person buys goods. Naomi, Elizabeth, and John's lives thus unfold in the moment as conjunctions between themselves and coded objects (e.g., bank cards), infrastructures (e.g., mobile phone networks), processes (e.g., direct debit billing), and assemblages (e.g., the Underground). Their worlds are being brought into being in situ as coded practices-practices produced through the conjunction of the technicity of coded objects, infrastructures, and processes, and their mediation through human action. For example, the technicity of the computerized check-out is combined with the action of Naomi to transduce a financial transaction. If the computer "crashes" or Naomi does not perform her role, the transaction either does not occur or occurs differently than how it was intended. It should be noted that most transductions occur automatically and ambivalently, that is, they do not require conscious thought by the person solving the problem.

\section{Code and Space}

Coded practices make a difference to Naomi, Elizabeth and John's lives, not simply because they effect mobilities, interactions, and transactions, but because they modulate space. The use of code makes a difference to the form, function, and meaning of space, which is endlessly (re)created in the moment. As such, to explain why software makes a difference to everyday lives necessitates an ontogenetic understanding of space.

The ontology of space has changed markedly over time. Most geographers until relatively recently adopted (implicitly, if not explicitly) an absolute ontology of space (Shields 1997). Within an absolute ontology of space, space is understood as a geometrical system of organization, "a kind of absolute grid, within which objects are located and events occur" (Curry 1995, 5). This grid is defined and understood through Euclidean geometry (with $x, y$, and $z$ dimensions) and treated analytically as "an absolute container of static, though movable, objects and dynamic flows of behaviour" (Gleeson 1996, 390, our emphasis). This absolute ontology of space is essentialist in formulation. It effectively reduces space to its geometric essence and depicts that essence as natural and given.

Recently, this viewpoint has been challenged by relational ontologies that understand space as being constituted and given meaning through human endeavor. Within these relational ontologies, space is not a given, neutral, and passive geometry but rather is produced through social relations. Space, it is posited, is not essential or objective in nature, but produced: "constituted through social relations and material social practices" (Massey 1994, 254). This relational view is perhaps most fully developed by Lefebvre (1991). The consequence of relational ontologies of space, as M. Crang and Thrift (2000) detail, is that space assumes a variety of new formulations, especially to those outside the discipline of geography, where it has taken on metaphorical qualities that seem far removed from absolute conceptions of "space as container." As a result, space can be conceived to exist separate from social conceptions of space, or taken to always be social (Hubbard et al. 2002). Equally, space can be conceived as fixed outside time, or always in a "state of becoming," known only in, and through, time (Unwin 2000).

The three vignettes highlight the latter point, that as people traverse space, individual mobilities, interactions, and transactions in conjunction with code (that is, coded practices) beckon space into being. The coded practices of Naomi, Elizabeth, and John constantly transformed the form, function, and meaning of space, where space is conceived as a combination of material fabric (form) and associated spatiality (function and meaning) that is constantly being remade. Space in these terms is not ontologically predetermined or defined, it is ontogenetic.

This ontogenetic conception of space acknowledges that the forms and spatial relations of the world around 
us are clearly not static and fixed; they are constantly being altered, updated, and constructed in ways that alter sociospatial relations. At a macroscale, there are new local, regional, and national development schemes that are constantly in the process of transforming and regenerating built and transport infrastructure and "natural" environments. For example, modifications in road layout, new buildings, and infrastructure, a new city airport, the introduction of the "ring of steel" and the congestion charge zone, and the usage of wide-scale CCTV have radically altered the physical landscape and space-time relations of the city of London (through processes of convergence, compression, and distanctiation: see Janelle 1969; Harvey 1989; Giddens 1990). At a more microscale, infrastructure is constantly being modified, repaired, redesigned, and so on, so that streets and rooms are constantly in a process of being refashioned and remodeled and spatial layouts modified. For example, streets are dug for cabling, shop fronts updated, shop interiors redesigned, trees planted, buildings painted, grass mowed, litter dropped, and so on. In other words, space is constantly (re)created, most often in subtle and banal ways, but sometimes more dramatically.

Similarly, the functions of spaces are not static but alter with time (e.g., seasonally: tourist destinations; daily: day- and nighttime economy), and the use of space is negotiated and contested between individuals and groups (Cresswell 1996; Mitchell 2003). Spaces thus have multiple functions and are used differently by individuals. For example, Trafalgar Square in London functions as somewhere to meet, to have lunch, to chat, to visit museums, to gather for protests, to party, to take tourist photos, and so on. In all these cases, the function of space is constantly created in the moment, usually as a collective manufacture composed of the recursive interactions between different users.

Likewise, the meanings associated with spaces shift, changing with mood, action, memory, events, and so on. To return to the example of Trafalgar Square, the meanings associated with it vary as a function of how the space is used (as tourist or Londoner), how the viewer interprets Nelson's Column and the surrounding buildings (as visually stimulating scenery or imperialist celebration), the social background and attitudes of a person, that person's memories and understandings of the square, and so on. Likewise, meanings attached to home, work, buildings, and routes mutate over time. The meaning of space is therefore never static, but emerges, varying over time and across people and context.

Space, in these terms, is a practice, a doing, an event, a becoming-a material and social reality forever (re)created in the moment. To paraphrase Star and
Ruhleder's earlier quote, space is not a container with pregiven attributes frozen in time; rather, space gains its form, function, and meaning in practice. Space emerges through a process of ontogenesis.

Ontogenetic understandings of space have started to be examined by others, notably through Gillian Rose's reworking of Butler's $(1990,1993)$ theory of performativity. Rose $(1999,248)$ argues that "space is a doing, that does not pre-exist its doing, and that its doing is the articulation of relational performances ... space then is not an anterior actant to be filled or spanned or constructed ... [i]nstead, space is practised, a matrix of play, dynamic and iterative, its forms and shapes produced through the citational performance of self-other relations." To Rose, space itself, and thus its production, is brought into being through performativity. While Rose's formulation has utility, it is more profitable, we believe, following our earlier discussion, to think of the ongoing production of space as one of transduction in which performativity is one component, and the salience of objects and nonhumans another. Space in these terms is ontogenetically produced through transductive individuations. Space is thus constantly being brought into being as an incomplete solution to a relational problem.

In the vignettes, one of the predominant relational problems was an ongoing encounter between the individual and the built environment, where the problems were navigating and negotiating the buildings and infrastructures of the city and the solution, to a greater or lesser extent, was code. For example, as we examine in detail below, code regulated the traffic lights and speed cameras, the functioning of the Underground, and the security measures required to enter buildings. Other relational problems where the solution was code dependent concerned communication (e.g., communicating by mobile phone and Internet), domestic living (e.g., cooking dinner using a microwave), work (e.g., accessing patient files), and consumption (e.g., processing payment transactions). In these cases, for the entire period that code is employed as the solution to the relational problem, a particular kind of transduction is occurring wherein code induces a particular modulation of space.

\section{Spatial Transductions}

Coded objects, infrastructures, processes and assemblages, and the technicity they engender, transduce space-beckon new spatial formations and spatiality into existence-in three related ways.

Code/space refers to a transduction wherein the relational problem cannot be solved without code. Here, code dominates the transduction of space to the extent 
that the transduction is dependent on code. For example, without code, Naomi cannot scan goods and process payments that allow the shop to function, Elizabeth cannot travel on the Underground, and John cannot hold a transnational business meeting. In all three cases, coded objects, infrastructures, and processes have entirely replaced older (wholly manual, electromechanical) systems, meaning that they can no longer be undertaken in an alternative way. Shops, particularly chain stores and supermarkets, given the volume of turnover, are reliant on systems that scan barcodes. Staff are not trained to process goods manually, they no longer rotelearn the price of goods, and prices are not usually printed on items. Consequently, in such cases, if the code in the point-of-sales till fails to operate, or the product order/supply information system "crashes," or the network supporting the information system is "down," shop staff have no way of processing a customer's shopping. In other words, the shop fails to be a place where items can be bought and, instead, becomes a temporary warehouse until such time as the code functions again. Similarly, in Elizabeth's case, if the system that controls the signaling in the Underground "crashes," then the transport infrastructure grinds to a halt because the old manual system has been replaced (rather than merely supplemented); passengers become stranded and must seek alternative travel arrangements until the system is brought back online. Likewise, if the code supporting the communication between Singapore and John's office "fails," then the boardroom is not transformed into the desired transnational meeting room as the required effect of distanciation is not supported.

In these cases, code and space are dyadic, with the relationship so mutually constituted that if one half of the dyad is put "out of action," then the entire intended spatial transduction fails (the shop does not operate as a shop, the Underground does not facilitate travel, the transnational meeting space is not produced) (see Dodge and Kitchin 2004 for other examples related to air travel). In other words, because the technicity of code is transformed from high effect to low through its "failure," space cannot be brought into being as intended in order to solve the relational problem posed (buying groceries, traveling across the city, discussing business between offices); the transduction, and therefore the form, function, and meaning of space, is alternatively modulated.

Coded space is a transduction mediated by code, but differs from code/space in that the relationship between code and space is not dyadic (mutually constituted). Here, code matters to the transduction of a space, but if the code does not work as intended or not at all, the space continues to be brought into being largely as intended, although not necessarily as efficiently or least costly or safely. Code mediates the solution to a spatial problem, but it is not the only solution available. In other words, code's role is mostly one of augmentation and facilitation, rather than control and regulation. For example, the networked surveillance camera system in the store Naomi works in modulates a particular form of transduction by (potentially) affecting customer and staff behavior, but if the camera does not work, the shop still functions as a shop, in that it can still sell goods. Similarly, if the "next bus" digital displays and warning messages at the bus stops on Elizabeth's route to work cease to function, the bus stop continues to function as a location from which passengers can catch a bus (they just do not know the exact time the bus will arrive). Likewise, if the system that monitors the zone of the Congestion Charge "crashes," vehicles can still access and travel this part of London, but they will not be recognized and charged. In all these cases, code modulates the form, function, and meaning of space; it affects how space is brought into being, but it is not essential to enable a suitable transduction to occur that solves the relational problem.

Background coded space occurs where code has the potential to mediate a solution if purposefully activated. Potential codings include local, but turned-off, sources of code such as coded objects and infrastructures (e.g., water, electricity), and GPS, radio, and mobile phone signals that are always present, but mute until activated. Once the code is activated, the transduction of space is alternatively modulated to one of coded space or code/ space. For example, the mobile phone answered in a restaurant not only alters the nature of that space for the person answering the phone, but also those around him or her. In the case of water or electricity, code does not obviously or explicitly mediate the solution of accessing supply (e.g., turning the tap), but it is an important component that is several steps removed from the remit of the individual filling a glass with water. As we noted above, just about all utility infrastructures are now reliant (to some degree) on code for their functioning.

Given that coded infrastructures are distributed, the extensibility of the transduction of space is an important aspect to consider. The transduction of space by code does not simply consist of localized individuations. Instead, it is more productive to conceptualize the transduction of space through code as ongoing individuations across networks of greater or shorter length. In this sense, a complex, progressive conception of space is produced, wherein people and things are located within complex networks of mobilities, interactions, and 
transactions that bind them together across scales. In the case of the instantaneous nature of coded infrastructure and processes, scales such as "local" and "global" become redundant, with each network simultaneously connecting all locations within the network. Such a conceptualization thus renders fixed spatial boundaries and scales problematic (Whatmore and Thorne 1997; Amin and Thrift 2002). Moreover, it recognizes that each network is just one of a multitude of networks, thus creating multiple, simultaneous but partial, spatial-time configurations that are at once "local" and "beyond." Such scaleless configurations induce a constant mode of timespace distanciation, although they do not necessarily mean that decisions or actions at one location produce material outcomes at another. For example, the use of the ATM by Elizabeth leads to the communication with and updating of a banking database located somewhere else in the world but does not change the material conditions there. This is not to deny that for each individual these networks, and the transduction of space they help induce, occur at the site at which they are physically located. Rather, it is to acknowledge that this localized transduction is the grounding of one part (or several) of a complex, geographically distributed network(s), and that this grounding might be just one of a number that are simultaneously happening across the network. Here, the network becomes "a mass of currents rather than a single line of force" (Whatmore and Thorne 1997, 291) and is a "performative ordering (always in the making) rather than a systematic or structural entity (always already constituted)" (Whatmore and Thorne 1997, 289).

The creation of coded assemblages, coupled with the complexities of people's lives, means that it is often the case that several forms of code simultaneously modulate space, creating unique, hybrid, spatial formations and spatiality. For example, an individual may be using a mobile telephone, while cooking dinner using a microwave, while a digital television is on in the background. Here, different forms of code interact or coalesce to produce a particularized transduction of space: a hybrid composed of forms of code/space and coded space. Alternatively, the same locale might be transduced differentially for different individuals, for example, as coded space for a pedestrian waiting to cross a road and code/ space for a car driver. This means that the coded transduction of space is never fixed and shifts with place, time, and context. Here, the combination of many individuals occupying or interacting with the same locale, plus the many coded infrastructures and processes they are at that moment connected to, each beckoning space into being in relation to code, transduces complex spatial formations and spatiality. This means, of course, that the experience of individuals located in backgrounded coded space can be mediated by others transducing code/space. For example, a person talking loudly on a mobile telephone in a restaurant shapes the experience of the meal for the other diners. In this sense, space is a "collaborative manufacture" (P. Crang 1994, 686), a collective, heterogeneous series of transductions.

It should be noted that this conceptualization of space as an ontogenetic, collaborative manufacture does not deny the salience of structural forces such as political economy or capitalism or neoliberalism or institutional structures such as the state and its agencies; rather, it refigures all of these elements as sets of ongoing, relational, and contingent discursive and material practices that are citational and transformative. These practices, too, are in a state of ontogenesis, always being remade in ongoing processes, and inducing transductions in collective life. These structures do not sit outside of collective life, but are (re)made through its performance, providing citational context at the same time that they are perpetuated.

\section{Code as Incomplete Solutions to Relational Spatial Problems}

The modern city exists as a haze of software instructions. Nearly every urban practice is becoming mediated by code (Amin and Thrift 2002, 125).

Conceptualizing space ontogenetically, constantly coming into being through transductive processes as an incomplete solution to a relation problem, helps to explain why code makes a difference to everyday life. As the vignettes illustrate, while there are substantial differences between Naomi, Elizabeth, and John in personal circumstances, income, employment, lifestyle, housing, and so on, code was integral to how all three solved the relational problems of undertaking domestic tasks, traveling between locations, conducting work, communicating between people, and practicing consumption. Code, by altering the components, practices, and infrastructures of domestic living, travel, work, communication, and consumption, transduced new spatial formations and spatiality, alternatively modulating the home, streets, workplaces, shops, and so on.

\section{Domestic Living}

In all three cases, the tasks and routines (the relational problems) of everyday home life were augmented, mediated, and regulated by code. For example, John was 
awakened by a digital alarm clock, Elizabeth cooked her evening meal using a programmable microwave, and Naomi and her children watched satellite television and played a computer game. Code, once activated, transduced the material and social conditions of John's bedroom, Elizabeth's kitchen, and Naomi's living room, while continued interaction with the code consisted of individuations up until interaction ceased and a new transduction occurred or other coded objects or infrastructures were activated, creating a new hybrid transduction. Such transductions are commonplace, given that entertainment and play are increasingly reliant on coded objects that are enabled by several coded infrastructures (e.g., Internet, cable television, electricity).

While the use of code here is enabling-it facilitates waking, cooking, and entertainment-in other cases, it is used in domestic settings to regulate and discipline. This function is most obviously revealed when Naomi checks the status of her prepaid electricity meter to determine whether the payment card needs topping up. The code disciplines her use of electricity against her means to pay. In Elizabeth and John's cases, their use of domestic utilities is monitored centrally, and the bills (or receipts if direct debited) are mailed to them. Further, both Naomi's and John's homes are subject to a different kind of surveillance. In Naomi's case, the entrance to the tower block is surveyed by cameras linked into a wider, public-housing surveillance network. John's home is protected by a alarm system, with software-monitored motion sensors, networked into a private security company, which will respond to its activation if it is not turned off within thirty seconds of someone entering the house.

Surveillance systems can be seen as a key assemblage in the "societies of control" (Haggerty and Ericson 2000), of which video surveillance is a key form of coded infrastructure that, because of its growing pervasiveness, is featured in all classes of relational problems concerning public space (e.g., on the street, road traffic), semipublic space (e.g., shopping mall, public transportation, hospital, pub), and private space (e.g., home, office building). On a typical day, the average person living in London is "filmed by over three hundred cameras on over thirty separate CCTV systems" (Norris and Armstrong 1999, 42). McCahill and Norris $(2002,20)$ make an educated "guesstimate" that there are some half a million cameras in London, giving around one camera for every fourteen people. The geographical distribution of cameras across space is uneven, and their level of ownership and technical sophistication also vary (Graham 1998, 2002). Most are basic analogue systems (and may not even be recorded), some are dummy cameras that the installers hope will exploit the deterrent effect, and others are networked systems. The latter are highly coded infrastructures, increasingly built around software algorithms to sort and classify the observed. Surveillance in different contexts is discussed further in each of the following sections.

\section{Traveling}

The movement of people and goods is essential for society to function. The relational problem to be solved is one of transferring people and goods from one location to another. Even though all three of our cases used different modes of travel throughout the day-walking, Underground train, lift, escalator, car-the journeys of all three were at some point solved (facilitated and regulated) by code. In the case of Elizabeth's use of the Underground and John's use of car transport, these transport systems have become dense assemblages centered around a particular coded infrastructure. Here, code is primarily employed as an operational management/control-related (e.g., payment, flow, maintenance) or surveillance/regulation-related (e.g., security, safety, taxation/licensing) tool. These functions are often highly interlinked so that management is augmented by surveillance that not only monitors flow and speed but also aims to discipline passenger and driver behavior.

The London Underground network handles 3 million passenger journeys daily and is reliant on code for its complex day-to-day operation on over 253 miles of track and 275 stations, from the ticketing of passengers (payment by credit/debit card or Elizabeth's use of a smart card or the validation of tickets at station turnstiles) to the operation of lifts and escalators; track management using a transponder system that monitors the real-time location of trains; control and monitoring of signaling; fire and smoke detection and alarm systems; displays that update passengers on the arrival of trains; computation of timetables and routes; staffing schedules; revenue and account databases; and embedded code in the trains themselves. Further, Elizabeth is subject to the gaze of a raft of networked surveillance cameras that monitor the entrances, passageways, platforms, and train carriages. These cameras are accompanied by automated, loudspeaker security messages that play every few minutes. As Elizabeth traverses the foyers, escalators, passageways, and trains of the coded assemblage of the underground, she (and her fellow passengers and staff) beckon into being a hybrid mix of coded space and code/space as a series of collective transductions. The London bus network consists of a similar assemblage. 
John likewise travels through a road system that is increasingly managed and surveyed using code. Strategic planning is done using traffic simulations and software models of the road system; road maintenance and upgrading is planned using a GIS. Transport for London employ a network of forty-five cameras in order to monitor and coordinate traffic flow at strategic locations. ${ }^{5}$ This system also feeds the media with congestion reports and updates an information website. Traffic-light sequencing is controlled using a comprehensive traffic management system. This system is augmented by speed cameras (there are approximately 650 speed cameras on London roads; McCahill and Norris 2002), mobile speed camera vans, red-light cameras, bus-lane and busmounted cameras that aim to discipline driver behavior (in these cases, from not driving too fast, not jumping red lights, and not occupying bus lanes). Most of these cameras are networked, and increasingly, they use an Automatic Number Plate Recognition (ANPR) system to pattern-match license plate numbers with owners and automatically print and post fines. Because John is driving to the center of the city, he is also subject to two special systems. The "ring of steel" consists of a sophisticated set of surveillance cameras that continuously monitors all traffic entering and leaving the City (the financial services area of London), introduced after IRA terrorist attacks in 1993 (Coaffee 2004). In addition, eight square miles of central London are regulated by a "congestion charge" payment system introduced in February 2003, again monitored and coordinated using a set of 688 networked cameras at 203 sites. $^{6}$ This system uses a centralized ANPR system to ensure payment. Even the final few yards of John's journey are regulated by a transponder-operated barrier into his office car park. Further, John's car is a sophisticated coded infrastructure, reliant on an engine management system, augmented by digital radio that updates him with real-time traffic reports, and an in-car navigation system that plots his position and can guide him along a route. Such is the "power" of the code within the engine management system that if the system fails, the car will not function. John's use of the car is also mediated by coded processes related to driving licenses, vehicle ownership, insurance, road tax, and road worthiness. Similar to the case in Elizabeth's use of public transport, then, John and his fellow drivers beckon a mix of coded spaces into being. Thus, all mechanized elements of mobility in large Western cities are coded to some degree, and the level of coding is increasing as more and more sophisticated telematics schemes are designed and deployed in an effort to "fix" the capacity constraints in congested urban areas.
Naomi and Elizabeth are not subject to active travel management via code while walking, but they are subject to the disciplinary gaze of a variety of public and private cameras that survey the street and underpasses. These cameras, while producing coded space, are little noticed by either woman due to their familiarity. Their effect on the individuations of spatial behavior is minimal. As such, in this case, while the code does affect the transduction of space, the awareness and impact of this transduction is low. That said, without surveillance, both women might feel less safe and more insecure as they traverse the city, and they might have taken different routes (see Koskela 2000 for discussion). Moreover, this is not to say that the street is not managed by a number of overlapping coded processes (e.g., local government software for scheduling street cleaning and GIS inventory for signs and street furniture, pollution monitoring, police databases on street crimes, etc.) and coded infrastructures (e.g., computer-managed street lighting, centrally controlled sequencing of pedestrian crossing lights, and so on). In other words, all forms of travel infrastructure and their maintenance, regulation, and operation, are increasingly becoming reliant on code.

\section{Working}

Work consists of a series of relational problems concerning the production of goods and services. In order to solve these problems and fulfill orders and mandates, the workplace environment is increasingly dependent on code, with most workplaces' (particularly those of large organizations and multinationals) nodes in an extremely complex and dense assemblage of coded infrastructures and processes. These include utilities; logistics networks; customer, employment, and product management systems; intranets, and so on. Code is now the structural "glue" that binds distributed and distanciated corporate activities together. In all three of our vignettes, the jobs performed - the transductions of workspace-are highly code dependent. For example, Naomi spent most of her working day sitting at the checkout, scanning barcodes, updating loyalty cards, and processing customer payment by credit/debit cards. Elizabeth used code-dependent specialist machines for monitoring patients in the operating room and coded processes for looking up and updating patient health records. John used a computer to compile a report, a PDA to organize his meetings and transport files, and a company intranet to monitor the financial markets and the trading of stocks and shares. Moreover, all three work in environments that are heavily surveyed. Naomi's store employs surveillance cameras in the shopping area, the stock rooms, and 
loading bays; her use of the till is monitored (indeed, a number of companies now not only monitor number of key strokes, length of breaks, telephone calls, and e-mail, but also review computer files, see Ball and Wilson 2000); the customers' credit/debit cards are checked for their status and balance. Elizabeth and John have to use swipe cards to gain access to certain parts of the hospital or office building, respectively, which means all movement can potentially be logged, tied to individuals' records, and recalled and analyzed at some future time. All three gain access to computer systems with usernames and passwords. For Elizabeth and John, code-dependent communication using e-mail, phone, and fax is also a vital component of workplace practices. The consequence of such heavy reliance on code for work practices is that work environments are constantly being brought into being as hybrid mixes of coded space and code/ space.

\section{Communicating}

Code has become central to solving the relational problem of facilitating the communication between people over distances. Code is now integral to the operation of communication infrastructures, many of which exist purely as a result of developments in software engineering. In all three vignettes, with the exception of face-to-face conversations, all communication between people took place via the coded infrastructures of telecommunications: mobile phones, conventional phones, fax, pagers, and e-mail. As noted by others, these technologies have profound impacts on space-time by allowing instantaneous communication across distance, and in the case of mobile phones and pagers, between moving devices. Such devices enable "always-on" communication that is transforming work and leisure practices. For the duration of any call, a transduction of code/ space occurs as the call alters individual performativity at the time a call is initiated or answered until the call is terminated. Consequently, any call, text, page, fax, and so on, means a transduction of code/space occurring simultaneously at the two places connected. For example, Elizabeth's mobile telephone text message to her friend Sally led to a simultaneous transduction that altered the performativity of Elizabeth's walk to work and whatever activity Sally was doing when she received the text. In the case of mobile phone texting or e-mail, a transduction occurs for one party when sent and the other when read (see Adams 1995 on issues of technology and human extensibility).

While the above communication infrastructures are entirely dependent on code, the delivery of conventional mail has also been massively augmented by code. Given the depth of embedding of code into mail systems, code has become vital to the day-to-day sorting and delivery of mail. Interestingly, most conventional mail now consists of bills and statements related to coded processes, along with junk mail targeted by customer profiling and geodemographics, as illustrated by the delivery of Elizabeth's compact discs and targeted vouchers and John's utility bill.

\section{Consuming}

The coded assemblages of financial services, logistics, and shop/leisure facilities provide solutions to the relational problems of supplying and buying goods and services. Elizabeth's use of an ATM connects her into the bank's coded infrastructure and uses coded processes to assess her status and dispense cash. John's use of his credit card to purchase lunch performs a similar operation. Naomi's use of electricity is defined by how much credit has been charged onto a payment card. These coded dealings leave a personal, digital, traceable trail of transactions, as opposed to Elizabeth's cash purchase of lunch (although this transaction appears in the coded processes related to the café such as tax returns). These transactions are constructed into a product in the form of customer profiling and geodemographics and used in marketing campaigns (hence Elizabeth's targeted marketing and John's junk mail). (See Goss 1995; Curry 1997 for discussion of some of the implications of geodemographic profiling.) In addition, purchases are increasingly tied into stock and logistics systems that track sales and place orders. Consumption of services and leisure now also occurs across coded infrastructures. Elizabeth buys her insurance by telephone, she buys books and checks her dating agency service online, and she consumes other Web pages. Naomi buys a lottery ticket using a dedicated intranet accessed via a shop. And conventional leisure services are now augmented by code, such as that in the monitors that track John's performance and health in the gym. In all these examples, the spaces of consumption-the shop, the gym, the bank-are citationally remade as coded spaces (gym) and code/space (shop/bank); code makes a difference to the form, function, and meaning of the space.

\section{Conclusions}

[T]ransduction aids in tracking processes that come into being at the intersection of diverse realities. These diverse realities include corporeal, geographical, economic, conceptual, biopolitical, geopolitical and affective dimensions. They entail a knotting together of commodities, signs, 
diagrams, stories, practices, concepts, human and nonhuman bodies, images and places. They entail new capacities, relations and practices whose advent is not always easy to recognize (Mackenzie 2002, 18).

There is little doubt that code is increasingly active in the production of everyday life. As the vignettes illustrate, code is routinely embedded in objects such as washing machines, alarm clocks, televisions, lifts, and cars to augment their use, thus creating coded objects. In many of these cases, the code has replaced the means by which they previously used to work, so that if the code fails, then the object fails to operate. For example, if the code that controls the wash cycle on a washing machine fails, the machine will not operate at all. Likewise, infrastructures such as transport and logistics networks, communication and broadcast entertainment networks, and utility networks, rely extensively on code for their operation. For example, code is used to plan, monitor, manage, and regulate flow of a commodity across a network and in the measurement of usage and billing of customers. Information related to individual and institutional finance, taxation, insurance, health, crime, education, utility usage, service usage, and so on are routinely held in digital databases that are accessed and managed using information systems and thus consist of coded processes. Coded objects, infrastructure, and processes, when used in relation to each other, entwine to create coded assemblages that permeate the practices of institutions and industries.

Code makes a difference to everyday life because it possesses high technicity, that is, the power to make things happen; code mediates, supplements, augments, monitors, regulates, operates, and facilitates many everyday tasks and routines related to domestic living, travel, work, communication, and consumption. This power to affect change is not deterministic but is contingent and relational, the product of the conjunction between code and people. In other words, code and human life are produced through or folded into each other, taking the form of coded practices. As practices occur as ongoing processes and events-as partial, always incomplete, solutions to relational problems-it follows that code and human life need to be conceived as unstable and always in a state of becoming. And since practices happen somewhere and have material, spatial, and social outcomes, space, too, is endlessly re-created in the moment. Space is a continuous process of matter and meaning taking form as divergent realities-technical and nontechnical, human and nonhuman, living and nonliving - constantly come into contact to create new conditions. Reading the vignettes as catalogues of on- togenetic coded practices, it is clear that code makes a difference to everyday life because it alternatively modulates space. The form, function, and meaning of space are transduced by code.

Code modulates space by significantly altering the conditions through which space is continually beckoned into being. Code transduces space into two generic forms and is ever present in a third. Code/space is a form of transduced space wherein the production of space is wholly dependent on code, so that the relationship between code and space is dyadic. If the code "fails," then the entire transduction "fails" (is alternatively modulated). Coded space is where space is transduced by code, but the transduction is not dependent on code; code matters to the ontogenesis of space, but if the code "fails," space continues to be transduced. Background coded space is where code is present and has the potential to transduce space if purposefully activated. Since transduction is a function of the conjunction of people and the technicity of code, it follows that the transduction of space is similarly contingent and relational, varying as a function of the nature of the code and person, and with context. By understanding space to be ontogenetic, the vignettes demonstrated that code transduces space into code/space or coded space in an effort to provide a solution to a relational problem. In the vignettes these relational problems included undertaking domestic tasks, traveling between locations, conducting work, communicating between people, and practicing consumption. Code sought to partially solve these problems by alternatively modulating the home, streets, workplaces, shops, and so on.

This article has provided an initial analysis of the extent and impact of code on everyday life. In doing so, it has opened several potentially interesting lines of enquiry that warrant further attention and exploration. First, there is a need to more fully document the forms and functions of code in everyday life and the production of code itself. This documentation needs to consist of both synoptic overviews and more detailed case studies of particular coded objects, infrastructures, processes, and assemblages. Second, there is a need to further explore the merits of the theoretical framework advanced in relation to other theories of technology and society and to evaluate the concepts of technicity and transduction in relation to other forms of technology. Third, there is a need to think through what it means to theorize space as ontogenetic rather than as an ontology, not just in relation to code and technology but more broadly in terms of what it means for how we think about the production of space. Such a rethinking of space has started to occur in the past few years, most notably in 
work that has explored the notion of performativity, and its continuation will be an enormously productive exercise for geographical analysis.

\section{Acknowledgements}

We would like to thank Barney Warf, Rob Shields, Anne Galloway, James Monagle, and James Sidaway for comments and those who attended seminars at Carleton University, Queen's University, and University of Toronto at which this work was first publicly presented in 2003. We also acknowledge the helpful comments of Audrey Kobayashi and the Annals referees.

\section{Notes}

1. Software is said to "crash" when it ceases to function.

2. Ontogenesis refers to how something comes to be, as opposed to ontology, which refers to what something is.

3. Much of the infrastructure of the utilities has evolved over many decades as a patchwork of systems have been installed, upgraded, and interlinked. Their true extent and complexity remain largely hidden from public view (see Clayton 2000).

4. The fieldwork consisted of conducting detailed software and hardware audits for journeys taking place in local environments and across the city to work. Each of the routes was traced by both authors, and the location and type of coded object and infrastructure were documented in a field notebook, onto a 1:1250 scale map, and by taking photographs.

5. Details from Transport for London, http://www.tfl.gov.uk/tfl/ capitalcams/index.shtml (last accessed 30 July 2003).

6. Details from Congestion Charging fact sheets: Camera enforcement, Transport for London, http://www.tfl.gov.uk/tfl/ cc_fact_sheet_enforcement.shtml (last accessed 30 July 2003).

\section{References}

Adams, P. C. 1995. A reconsideration of personal boundaries in space-time. Annals of the Association of American Geographers 85:267-85.

Amin, A., and N. Thrift. 2002. Cities: Reimagining urban theory. Cambridge, U.K.: Polity Press.

Ball, K., and D. Wilson. 2000. Power, control and computer based performance monitoring: A subjectivist approach to repertoires and resistance. Organization Studies 21 (3): 539-65.

Bennett, R. F., and C. J. Dodd. 2000. Y2K Aftermath - Crisis Averted, Final Committee Report. The United States Senate Special Committee on the Year 2000 Technology Problem, 29 February. http://www.senate.gov/ y $2 \mathrm{k} /$ documents/final. pdf (last accessed 2 December 2003).

Butler, J. 1990. Gender trouble: Feminism and the subversion of identity. London: Routledge.

- 1993. Bodies that matter: On the discursive limits of sex. London: Routledge.

Clayton, A. 2000. Subterranean city: Beneath the streets of London. London: Historical Publications.
Coaffee, J. 2004. Rings of steel, rings of concrete and rings of confidence: Designing out terrorism in central London pre and post September 11th. International Journal of Urban and Regional Research 28:201-11.

Crang, M., and N. Thrift. 2000. Introduction. In Thinking space, ed. M. Crang and N. Thrift, 1-30. London: Routledge.

Crang, P. 1994. It's showtime: On the workplace geographies of display in a restaurant in Southeast England. Environment and Planning D: Society and Space 12:675-704.

Cresswell, T. 1996. In place/out of place: Geography, ideology and transgression. Minneapolis: University of Minnesota Press.

Curry, M. 1995. On space and spatial practice in contemporary geography. In Concepts in human geography, ed. C. Earle, K. Mathewson, and M. Kenzer, 3-32. Lanham, MD: Rowman and Littlefield Publishers.

. 1997. The digital individual and the private realm. Annals of the Association of American Geographers 87:681-99.

Dodge, M., and R. Kitchin. 2004. Flying through code/space: The real virtuality of air travel. Environment and Planning $A$ 36:195-211.

- Forthcoming. Codes of life: Identification codes and the machine-readable world. Environment and Planning D: Society and Space.

Giddens, A. 1990. The consequences of modernity. Cambridge, U.K.: Polity Press.

Gleeson, B. 1996. A geography for disabled people? Transactions of the Institute of British Geographers 21:387-96.

Goss, J. 1995. 'We know who you are and we know where you live': The instrumental rationality of geodemographics systems. Economic Geography 71:171-98.

Graham, S. 1998. The spaces of surveillant-simulation: New technologies, digital representations and material geographies. Environment and Planning D: Society and Space 16: 483-503.

- 2002. CCTV: The stealthy emergence of a fifth utility? Planning Theory and Practice 3:237-41.

Haggerty, K. D., and R. V. Ericson. 2000. The surveillant assemblage. British Journal of Sociology 51 (4): 605-22.

Harvey, D. 1973. Social justice and the city. London: Edward Arnold.

. 1989. The condition of postmodernity. Oxford, U.K.: Blackwell.

Hubbard, P., R. Kitchin, B. Bartley, and D. Fuller. 2002. Thinking geographically: Space, theory and contemporary human geography. London: Continuum Press.

Janelle, D. 1969. Spatial reorganization: A model and concept. Annals of the Association of American Geographers 59: 348-64.

Koskela, H. 2000. 'The gaze without eyes': Video-surveillance and the changing nature of urban space. Progress in Human Geography 24:243-65.

Latour, B. 1993. We have never been modern. New York: Harvester Wheatsheaf.

Lefebvre, H. 1991. The production of space. Trans. D. NicholsonSmith. Oxford, U.K.: Blackwell.

Mackenzie, A. 2002. Transductions: Bodies and machines at speed. London: Continuum Press.

. 2003a. The problem of computer code: Leviathan or common power? http://www.lancs.ac.uk/staff/mackenza/ papers/code-leviathan.pdf (last accessed 2 December 2003). . 2003b. Transduction: invention, innovation and collective life. http://www.lancs.ac.uk/staff/mackenza/papers/ transduction.pdf (last accessed 2 December 2003). 
Massey, D. 1994. Space, place and gender. London: Methuen. McCahill, M., and C. Norris. 2002. CCTV in London. Urban Eye Project, Working Paper No. 6. http://www.urbaneye.net (last accessed 2 December 2003).

Mitchell, D. 2003. The right to the city: Social justice and the fight for public space. New York: Guilford.

Norris, C., and G. Armstrong. 1999. The maximum surveillance society: The rise of CCTV. Oxford, U.K.: Berg.

Rabinow, P. 1999. French DNA: Trouble in purgatory. Chicago: University of Chicago Press.

Risks List. 2003. Computer error grounds Japanese flights. Forum on risk to the public in computers and related systems, 3 March 2003, 22(60). http://catless.ncl.ac.uk/Risks/22.60. html (last accessed 2 December 2003).

Rose, G. 1999. Performing space. In Human geography today, ed. D. Massey, J. Allen, and P. Sarre, 247-59. Cambridge, U.K.: Polity Press.

Shields, R. 1997. Spatial stress and resistance: Social meanings and spatialisation. In Space and social theory, ed. G. Benko and U. Strohmayer, 186-202. Oxford, U.K.: Blackwell.

Simondon, G. 1989a. Du mode d'existence des objets techniques. Paris: Editions Aubier-Montaigne. 1989b. Lindividuation psychique et collective. Paris: Editions Aubier-Montaigne.

1992. The genesis of the individual. In Incorporations 6, ed. J. Crary and S. Kwinter, 296-319. New York: Zone Books. . 1995. L'Individu et sa genèse physio-biologique. Grenoble: Editions Jerome Millon.

Star, S. L., and K. Ruhleder. 1996. Steps towards an ecology of infrastructure: Design and access for large information spaces. Information Systems Research 7:111-34.

Thrift, N., and S. French. 2002. The automatic production of space. Transactions of Institute of British Geographers 27:309-35.

U.S.-Canada Power System Outage Task Force. 2004. Final report on the August 14th blackout in the United States and Canada. https://reports.energy.gov/ (last accessed 2 December 2003).

Unwin, T. 2000. A waste of space? Towards a critique of the social production of space. Transactions of the Institute of British Geographers 25:11-29.

Whatmore, S. 2002. Hybrid geographies. London: Sage.

Whatmore, S., and L. Thorne. 1997. Nourishing networks. In Globalising food, ed. D. Goodman and M. Watts, 287-304. London: Routledge.

Correspondence: Centre for Advanced Spatial Analysis, University College London, 1-19 Torrington Place, London WC1E 7HB, U.K., e-mail: m.dodge@ucl.ac.uk (Dodge); Department of Geography, National University of Ireland Maynooth, Co. Kildare, Ireland, e-mail: rob. kitchin@nuim.ie (Kitchin). 